\title{
Analisis keselamatan dan kesehatan kerja (K3) pada pekerja di lingkungan Minas Gas Turbine (MGT) PT. Chevron Pacific Indonesia (CPI), Minas
}

\author{
Ali Imran ${ }^{1}$, Bintal Amin ${ }^{2}$, Sofia Anita ${ }^{3}$ \\ ${ }^{1}$ HSE Superintendent PT Adil Utama Consortium, Enviro Project. \\ ${ }^{2}$ Dekan Fakultas Perikanan dan Kelautan Universitas Riau. \\ ${ }^{3}$ Dosen Fakultas Matematika dan Ilmu Pengetahuan Alam.
}

*Correspondent email : ali.amran@atcproject.net

Diterima: 17 Februari 2021 | Disetujui: 28 Februari 2021 | Diterbitkan: 28 Februari 2021

\begin{abstract}
Human resources play an important role for the success of an organization or company, because humans are living assets that need special attention by the company. The fact that humans as a major asset in an organization or company must get serious attention and be managed as well as possible. In managing human resources, management is needed to be able to manage resources systematically, planned and efficiently. Of the many companies that move at high levels of potential hazards, one of them is the Oil and Gas Mining sector and in this sector work accidents often occur. In general, accidents are always interpreted as "unexpected events". Actually, every work accident can be predicted or suspected from the beginning if the actions and conditions do not meet the requirements. Statistics reveal that $80 \%$ of accidents are caused by unsafe acts, and only 20\% by unsafe conditions (Silalahi, 1991). Several studies in Indonesia have been carried out to analyze Occupational Safety and Health (K3) on other elements in the company, including in the oil, gas and geothermal sectors, but the results are not always significant. PT. Chevron Pacific Indonesia (PT. CPI) is one of the largest oil, gas and geothermal energy companies in Indonesia. Many sections or departments in CPI are high-risk, one of which is the Minas Gas Turbine (MGT) found in the PGT department. The problems that exist are how a Safe Work Culture, Worker Competence, Work Safety Procedures and Regulations, Management Commitment (Economy) and Work Environment affect the Work Safety of Employees in the Minas Gas Turbine section of PT. Chevron Pacific Indonesia, Minas. By definition a turbine is a rotating machine that takes energy from the fluid flow. Simple turbines have one moving part, "rotor-blade assembly". One of the functions of the Minas Gas Turbine (MGT) is currently for power plants and gas producers whose uses are for production areas, offices, housing and buildings that are located around the production area. PT. Chevron Pacific Indonesia and has a $115 \mathrm{KV}$ voltage electricity network that is spread for transmission lines from one area to another. This is very influential on the safety track record of workers who become operational support as a whole. By examining some of the components that exist as research variables, it can be concluded that a Safe Work Culture, Worker Competence and Work Environment really needs special attention by the Project Management Team (PMT) in the Minas Gas Turbine section around 27.7-31.3\% While Work Safety Procedures and Regulations are a very strong variable influence on Employee Safety that is equal to $89.5 \%$. And there is a strong influence between Management Commitment (Economy) on Employee Safety, which is $47.6 \%$.
\end{abstract}

Keywords: analysis; occupational safety and health; minas gas turbine; rank spearrman

Keselamatan dan Kesehatan Kerja (K3) merupakan aspek yang penting dalam suatu perusahaan. Salah satu yang berkaitan erat dengan K3 adalah kecelakaan kerja. Terjadinya kecelakaan kerja tentu saja menjadikan masalah yang besar bagi kelangsungan sebuah perusahaan. Kerugian yang diderita tidak hanya berupa kerugian materi yang cukup besar, namun lebih dari itu adalah timbulnya korban jiwa yang tidak sedikit jumlahnya. Kehilangan sumber daya manusia ini merupakan kerugian yang sangat besar, karena manusia adalah satu-satunya sumber daya yang tidak dapat digantikan oleh teknologi apapun. Menurut peraturan undang-undang Ketenagakerjaan yaitu UU No. 1 Tahun 1970, setiap pekerja/buruh berhak atas perlindungan keselamatan dan kesehatan kerja. Kemudian yang terbaru,

Kemudian ada Peraturan Menteri Ketenagakerjaan Republik Indonesia Nomor 5 Tahun 2018 Tentang Keselamatan dan Kesehatan Kerja Lingkungan Kerja. Dalam Peraturan Menteri ini yang dimaksud dengan Keselamatan dan Kesehatan Kerja yang selanjutnya disingkat K3 adalah segala 
kegiatan untuk menjamin dan melindungi keselamatan dan kesehatan tenaga kerja melalui upaya pencegahan kecelakaan kerja dan penyakit akibat kerja.

Secara umum untuk sektor migas seperti PT. Chevron Pacific Indonesia K3 sangat jadi perhatian dalam setiap aktifitas yang ada. Bila semua karyawan dan kontraktor (Business Partner) di lingkungan PT. Chevron Pacific Indonesia dalam bekerja telah melaksanakan pekerjaan dengan perilaku selamat, maka diharapkan angka kecelakaan akan berada dibawah atau sama dengan angka Performance Measure (PM) yang sudah ditentukan. Namun pada kenyataannya, sejak diberlakukannya budaya kerja selamat pada Tahun 2007, kecelakaan kerja tetap saja tejadi (angka kecelakaan tertinggi pada bagian field Station PT. Chevron Pacific Indonesia secara keseluruhan dengan 3 kejadian) dan bahkan angkanya diatas PM, sehingga pencapaian angka dibawah PM OE HES dapat dikatakan belum pernah tercapai. Adapun faktor yang mempengaruhi Keselamatan Kerja Karyawan adalah: Budaya Kerja Selamat, Kompetensi Perkerja, Prosedur dan Peraturan Keselamatan Kerja, Komitmen Manajemen (Ekonomi) dan Lingkungan Kerja.

\section{METODE PENELITIAN}

Jenis penelitian ini adalah analisis dan survey karena penelitian ini menganalisis hubungan atau pengaruh antara variabel dengan variabel yang lain, yaitu Budaya Kerja Selamat, Kompetensi Pekerja, Prosedur dan Peraturan Keselamatan Kerja, Komitmen Manajemen (Ekonomi) dan Lingkungan Kerja sebagai variabel Independent dengan Keselamatan Kerja Karyawan sebagai varìabel Dependent. Adapun langkah yang dilakukan untuk melakukan analisis data serta menjawab tujuan dari penelitian ini adalah sebagai berikut: Pertama, Statistik Deskriptif digunakan untuk mendiskripsikan dan memberi gambaran terhadap objek yang diteliti melalui data sampel. Menggambarkan data dalam tabel dan grafik dimaksudkan untuk mempermudah memahami hasil yang berkaitan dengan menjawab tujuan penelitian (Boediono et al. 2004). Kedua Analisis Rank Spearman, analisis ini digunakan karena data-data yang digunakan bentuknya ordinal. Fungsi utama uji ini untuk mengukur apakah ada terjadi hubungan antara dua kekuatan, besaran, variabel, fenomena, kejadian, peristiwa, persepsi, pandangan, penilaian dan kegiatan. Selanjutnya Analisis regresi nonparametrik dikenal sebagai alat analisis statistik alternatif saat analisis parametrik tidak dapat digunakan. Analisis regresi nonparametrik adalah prosedur statistik yang tidak mengacu pada parameter tertentu. Dalam hal ini, teknik-teknik dalam regresi nonparametrik memenuhi kebutuhan ini karena tetap valid walaupun tidak diperlukan pemenuhan asumsi kenormalan galat dan hanya berlandaskan asumsi yang sangat umum.

\section{HASIL DAN PEMBAHASAN}

Minas Gas Turbine yaitu merupakan salah satu bagian dari bisnis CPI untuk pembangkit listrik dan penghasil gas yang pemamfaatannya untuk area produksi, perkantoran, perumahan dan gedung-gedung yang berada disekitar area produksi Penelitian dilakukan pada di Minas Gas Turbine PT. Chevron Pacific Indonesia di Kecamatan Minas, Kabupaten Siak, Provinsi Riau. Data dari semua sampel penelitian ini dapat dilihat di Tabel 1 .

Tabel 1. Data Responden Penelitian

\begin{tabular}{|c|c|c|c|c|c|c|c|c|c|c|c|}
\hline $\begin{array}{c}\text { Jenis } \\
\text { Kelamin }\end{array}$ & $\mathrm{N}$ & $\mathbf{( \% )}$ & $\begin{array}{c}\text { Usia } \\
(\mathrm{Th})\end{array}$ & $\mathrm{N}$ & $\mathbf{( \% )}$ & $\begin{array}{c}\text { Pendidikan } \\
\text { Terakhir }\end{array}$ & $\mathrm{N}$ & $\%$ & $\begin{array}{c}\text { Masa } \\
\text { Kerja } \\
(\mathrm{Th})\end{array}$ & $\mathrm{N}$ & $\%$ \\
\hline Pria & 85 & 97 & $31-56$ & 52 & 59 & SMA/SMK & 58 & 66 & $<5$ & 26 & 30 \\
\hline Wanita & 3 & 3 & $20-30$ & 36 & 41 & DIII/S1 & 30 & 34 & $>5$ & 62 & 70 \\
\hline & & & & & & & & & & & \\
\hline Total & 88 & 100 & Total & 88 & 100 & Total & 88 & 100 & Total & 88 & 100 \\
\hline
\end{tabular}

Sumber : Data sensus penelitian (2020)

Jumlah responden pada penelitian ini adalah 88 orang, dengan rincian Wanita 3\% (3 orang) dan Pria 97\% (85 orang). Pekerja yang berusia 20-30 tahun 41\% (36 orang), 31-56 tahun 59\% (52 orang). Pekerja yang memiliki pendidikan SMA/SMK sebanyak 66\% (58 orang), yang berpendidikan D-III/S1 berjumlah 34\% (30 orang). Masa kerja yang kurang dari lima tahun sebanyak 30\% (26 orang), dan lebih dari lima tahun sebanyak $70 \%$ (62 orang). 


\section{Pengaruh Budaya Kerja Selamat dengan Keselamatan Kerja Karyawan}

Berdasarkan hasil uji Regresi Nonparametrik yang dilakukan, adanya pengaruh Budaya Kerja Selamat terhadap Keselamatan Kerja Karyawan bagian Minas Gas Turbine (MGT) PT. CPI Minas yaitu sebesar 27,7\%. Sesuai dengan pendapat Geller (2001), mempromosikan perilaku aman di tempat kerja merupakan bagian penting dari manajemen keselamatan dan kesehatan kerja dan merupakan salah satu cara untuk mencegah terjadinya kecelakaan kerja.

Tabel.2. Analisis Regresi berdasarkan t Hitung \& t Tabel

\begin{tabular}{|l|c|c|c|c|c|c|}
\hline \multicolumn{2}{|c|}{ Model } & \multicolumn{2}{c|}{ Coefficients $^{\mathrm{a}}$} & \multirow{2}{*}{ Sig. } \\
\cline { 3 - 7 } \multicolumn{2}{|c|}{} & B & Std. Error & Beta & & \\
\hline 1 & (Constant) & 10.687 & 2.212 & & 4.8 & .000 \\
& & & & .526 & 5.7 & .000 \\
\cline { 2 - 6 } & Budaya Kerja Selamat & .547 & .095 & & \\
\hline
\end{tabular}

Kemudian Krause (2000) menyatakan, Program Behavior Based Safety (BBS) digunakan untuk menggambarkan program yang berfokus pada perilaku dan budaya pekerja sebagai salah satu penyebab terjadinya kecelakaan kerja untuk mencegah terjadinya kecelakaan kerja dan penyakit akibat kerja. Program Behavior Based Safety akan mengidentifikasi pekerja yang berperilaku tidak aman kemudian mengarahkan pekerja tersebut untuk berperilaku aman pada saat bekerja.

\section{Pengaruh Kompetensi Pekeria dengan Keselamatan Kerja Karyawan}

Berdasarkan hasil uji Regresi Nonparametrik yang dilakukan, adanya pengaruh Kompetensî Pekerja terhadap Keselamatan Kerja Karyawan bagian Minas Gas Turbine (MGT) PT. CPI Minas yaitu sebesar 38,6\%, hal ini mendukung teori Mohammed (2002) yang menyatakan, kompetensi pekerja dapat berupa pengetahuan, pengertian dan tanggung jawab pekerja terhadap pekerjaannya, pengetahuan terhadap resiko, menolak pekerjaan yang tidak aman, pekerja mempunyai sertifikat kerja sesuai pekerjaannya.

Tabel 3. Analisis Regresi berdasarkan t Hitung \& t Tabel

\begin{tabular}{|l|l|c|c|c|c|c|}
\hline \multicolumn{2}{|c|}{ Model } & \multicolumn{2}{c|}{$\begin{array}{c}\text { Unstandardized } \\
\text { Coefficients }\end{array}$} & $\begin{array}{c}\text { Standardized } \\
\text { Coefficients }\end{array}$ & \multirow{2}{*}{ Sig. } \\
\cline { 3 - 6 } \multicolumn{2}{|c|}{} & B & Std. Error & Beta & & \\
\hline 1 & (Constant) & 9.574 & 1.883 & & 5.086 & .000 \\
\cline { 2 - 6 } & $\begin{array}{l}\text { Kompetensi } \\
\text { Pekerja }\end{array}$ & .958 & .130 & .621 & 7.346 & .000 \\
\hline $\begin{array}{l}\text { a. Dependent Variable: Kompetensi Pekerja } \\
\text { b. Predictors: (Constant), Kompetensi Pekerja }\end{array}$ & & & \\
\hline
\end{tabular}

Pekerja dengan kompetensi yang baik akan meminimalisasi resiko terjadinya kecelakaan kerja dan berani menghentikan pekerjaan jika dalam kondisi tidak aman dan tidak selamat. Program Stop Work Authority merupakan suatu program yang memungkinkan setiap karyawan yang menyaksikan suatu tindakan tidak aman atau merasa bahwa kondisi tidak menjamin operasi yang aman untuk segera menghentikan pekerjaan tanpa pertanyaan (Hanford, 2008).

\section{Pengaruh Prosedur dan Peraturan Keselamatan Kerja Terhadap Keselamatan Kerja Karyawan}

Berdasarkan hasil uji Regresi Nonparametrik yang dilakukan, pada penelitian ini ditemukan adanya pengaruh Prosedur dan Peraturan Keselamatan Kerja terhadap Keselamatan Kerja Karyawan bagian Minas Gas Turbine (MGT) PT. CPI Minas yang sangat besar yaitu sebesar 89,5\%, hal ini sesuai dengan penelitian terdahulu yang menyebutkan prosedur dan peraturan merupakan faktor yang penting dalam keselamatan kerja. Prosedur dan langkah kerja yang ada dapat dilihat dari rangkuman Standart Operasional Prosedur (SOP) yang dipakai di area kerja. Menurut Sucipto (2014) Standart Operasional Prosedur adalah pendoman kerja yang harus dipatuhi dan dilakukan dengan benar dan berurutan sesuai instruksi yang 
tercantum dalam SOP, perlakuan yang tidak benar dapat menyebabkan kegagalan proses produksi, kerusakan peralatan dan kecelakaan. Kenyataan yang ada di Minas Gas Turbine (MGT) PT. CPI Minas saat ini jika Standart Operasional Prosedur (SOP) alat tidak ada maka pekerjaan tidak boleh dilaksanakan.

Tabel 4. Analisis Regresi berdasarkan F Hitung \& F Tabel

\begin{tabular}{|c|c|c|c|c|c|c|}
\hline \multicolumn{2}{|c|}{ ANOVA $^{\mathrm{a}}$} & $\begin{array}{c}\text { Sum of } \\
\text { Squares }\end{array}$ & df & Mean Square & F & Sig. \\
\hline 1 & Regression & 205.524 & 1 & 205.524 & 53.959 & $.000^{\mathrm{b}}$ \\
\cline { 2 - 7 } & Residual & 327.567 & 86 & 3.809 & & \\
\cline { 2 - 7 } & Total & 533.091 & 87 & & & \\
\hline
\end{tabular}

\section{Pengaruh Komitmen Manajemen (Ekonomi) Terhadap Keselarnatan Kerja Karyawan}

Berdasarkan hasil uji Regresi Nonparametrik yang dilakukan, pada penelitian ini ditemukan adanya pengaruh Komitmen Manajemen (Ekonomi) terhadap Keselamatan Kerja Karyawan bagian Minas Gas Turbine (MGT) PT. CPI Minas sebesar 47,6\%, hal ini mendukung penelitian yang telah dilakukan sebelumnya (Cheyne, 1998 dan Mohammed, 2002), yang menemukan bahwa faktor komitmen merupakan salah satu faktor utama budaya keselamatan kerja, tanpa komitmen dan dukungan dari pihak manajemen sangatlah sulit untuk meraih keberhasilan dalarn menjalankan program keselamatan.

Tabel 5. Analisis Regresi berdasarkan t Hitung \& t Tabel

\begin{tabular}{|c|c|c|c|c|c|c|}
\hline \multicolumn{7}{|c|}{ Coefficients $^{\mathrm{a}}$} \\
\hline \multirow{2}{*}{\multicolumn{2}{|c|}{ Model }} & \multicolumn{2}{|c|}{$\begin{array}{c}\text { Unstandardized } \\
\text { Coefficients }\end{array}$} & \multirow{2}{*}{$\begin{array}{c}\begin{array}{c}\text { Standardized } \\
\text { Coefficients }\end{array} \\
\text { Beta }\end{array}$} & \multirow[b]{2}{*}{$\mathrm{t}$} & \multirow[b]{2}{*}{ Sig. } \\
\hline & & $\mathrm{B}$ & Std. Error & & & \\
\hline \multirow[t]{2}{*}{1} & (Constant) & 4.379 & .704 & & 6.220 & .000 \\
\hline & $\begin{array}{c}\text { Prosedur dan Peraturan } \\
\text { Keselamatan Kerja }\end{array}$ & .820 & .030 & .946 & 27.110 & .000 \\
\hline \multicolumn{7}{|c|}{ a. Dependent Variable: Keselamatan Kerja Karyawan } \\
\hline \multicolumn{7}{|c|}{ b. Predictors: (Constant), Kompetensi Pekerja } \\
\hline
\end{tabular}

\section{Pengaruh Lingkungan Kerja Terhadap Keselamatan Kerja}

Berdasarkan hasil uji Regresi Nonparametrik yang dilakukan, pada penelitian ini ditemukan adanya pengaruh Lingkungan Kerja terhadap Keselamatan Kerja Karyawan bagian Minas Gas Turbine (MGT) PT. CPI Minas sebesar 31,3\%, hal ini mendukung teori yang dikemukakan oleh Mohammed (2002) yaitu lingkungan kerja yang nyaman mendukung pekerja seperti jangan ada saling menyalahkan bila ada tindakan tidak aman, atau terjadi kecelakaan, area kerja stabil rata, cahaya cukup dan nyaman, selalu bekerja dalam batas aman dan tidak ada tekanan. Lingkungan kerja sangat berperanam dalam mendukung program keselamatan kerja bila seluruh pekerja mengutamakan program keselamatan kerja. Tercermin dari tindakan seperti pekerja bersedia melaporkan kecelakaan yang terjadi, adanya komunikasi yang baik sesama pekerja, dan hubungan yang harmonis dan dinamis sesama rekan kerja. Selanjutnya yang tak kalah penting adalah analisa bahaya di tempat kerja sudah tercantum di job safety analysis (JSA).

Tabel 6. Analisis Regresi berdasarkan F Hitung \& F Tabel

\begin{tabular}{|c|c|c|c|c|c|c|}
\hline \multicolumn{7}{|c|}{ ANOVA $^{\mathrm{a}}$} \\
\hline \multicolumn{2}{|c|}{ Model } & $\begin{array}{l}\text { Sum of } \\
\text { Squares }\end{array}$ & $\mathrm{df}$ & Mean Square & $\mathrm{F}$ & Sig. \\
\hline \multirow[t]{3}{*}{1} & Regression & 477.246 & 1 & 477.246 & 734.951 & $.000^{\mathrm{b}}$ \\
\hline & Residual & 55.845 & 86 & .649 & & \\
\hline & Total & 533.091 & 87 & & & \\
\hline \multicolumn{7}{|c|}{ a. Dependent Variable: Keselamatan Kerja Karyawan } \\
\hline \multicolumn{7}{|c|}{ b. Predictors: (Constant), Prosedur dan Peraturan Keselamatan Kerja } \\
\hline
\end{tabular}




\section{KESIMPULAN}

Berdasarkan hasil analisis dan pembahasan maka dapat ditarik beberapa kesimpulan sebagai berikut: Terdapat pengaruh yang cukup kuat antara Budaya Kerja Selamat terhadap Keselamatan Kerja Karyawan yaitu sebesar 27,7\% di bagian Minas Gas Turbine PT. Chevron Pacific Indonesia di Minas. Terdapat pengaruh yang cukup kuat antara Kompetensi Pekerja terhadap Keselamatan Kerja Karyawan yaitu sebesar 38,6\% di bagian Minas Gas Turbine PT. Chevron Pacific Indonesia di Minas. Terdapat pengaruh yang sangat kuat antara Prosedur dan Peraturan Keselamatan Kerja terhadap Keselamatan Kerja Karyawan yaitu sebesar 89,5\% di bagian Minas Gas Turbine PT. Chevron Pacific Indonesia di Minas. Terdapat pengaruh yang kuat antara Komitmen Manajemen (Ekonomi) terhadap Keselamatan Kerja Karyawan yaitu sebesar 47,6\%, di bagian Minas Gas Turbine PT. Chevron Pacific Indonesia di Minas. Terdapat pengaruh yang cukup kuat antara Lingkungan Kerja terhadap Keselamatan Kerja Karyawan yaitu sebesar 31,3\% di bagian Minas Gas Turbine PT. Chevron Pacific Indonesia di Minas.

\section{UCAPAN TERIMAKASIH}

Penulis menyampaikan terimakasih kepada seluruh pihak yang membantu dalam kelancaran penelitian ini.

\section{DAFTAR PUSTAKA}

Boediono dan Wayan, K. 2004. Teori dan Aplikasi Statistika dan Probabilitas. Cetakan ketiga. PT. Remaja Rosdakarya Offset, Bandung.

Cheyne, A. C Sue, A Oliver. JM Thomas,.1998. Modeling Safety Climate in the Prediction of Level Safety Activity. Work and Stress, 12.3.255-257

Geller, E Scoot. 2001. The Pshychologi Of Safety Handbook. USA : Lewis Publiher.

Hanford, E. (2013). Angela Duckworth and the research on 'grit'. American Public Media. http://americanradioworks.publicradio.org/features/tomorrows-college/grit/angela-duckworthgrit.html

Krause, D. G. 2000. The Way of Leader. Diterjemahkan oleh PT Gramedia Dengan Judul Kiat Sang Pemimpin. Jakarta: PT Garamedia Pustaka Utama

Sucipto, CD. 2014. Keselamatan dan Kesehatan Kerja. Yogyakarta: Gosyen Publishing.

Pemerintah Indonesia. 1970. Undang-Undang Republik Indonesia Nomor 1 Tahun 1970 tentang Perlindungan Keselamatan dan Kesehatan Kerja. Lembaran RI Tahun 2006 No. 17. Jakarta: Sekretariat Negara.

Pemerintah Indonesia. 2018. Undang-Undang Republik Indonesia Nomor 5 Tahun 2018 tentang Keselamatan dan Kesehatan Kerja, Lingkungan Kerja. Lembaran RI Tahun 2018 No. 5. Jakarta: Sekretariat Negara.

Mohammed. 2002. Safety Climate in Constuction Site Environment, Journal of Contruction Engineering and Management, 85.245-251 